\title{
Post-hypothermic cardiac left ventricular systolic dysfunction after rewarming in an intact pig model
}

Ole Magnus Filseth ${ }^{1,2,3^{*}}$, Ole-Jakob How ${ }^{2,4}$, Timofei Kondratiev ${ }^{1,2}$, Tor Magne Gamst ${ }^{3}$, Torkjel Tveita1,2,3

\begin{abstract}
Introduction: We developed a minimally invasive, closed chest pig model with the main aim to describe hemodynamic function during surface cooling, steady state severe hypothermia (one hour at $25^{\circ} \mathrm{C}$ ) and surface rewarming.

Methods: Twelve anesthetized juvenile pigs were acutely catheterized for measurement of left ventricular (LV) pressure-volume loops (conductance catheter), cardiac output (Swan-Ganz), and for vena cava inferior occlusion. Eight animals were surface cooled to $25^{\circ} \mathrm{C}$, while four animals were kept as normothermic time-matched controls.

Results: During progressive cooling and steady state severe hypothermia $\left(25^{\circ} \mathrm{C}\right)$ cardiac output $(\mathrm{CO})$, stroke volume (SV), mean arterial pressure (MAP), maximal deceleration of pressure in the cardiac cycle ( $\mathrm{dP} / \mathrm{dt}_{\mathrm{min}}$ ), indexes of LV contractility (preload recruitable stroke work, PRSW, and maximal acceleration of pressure in the cardiac cycle, dP/ $d t_{\max }$ ) and LV end diastolic and systolic volumes (EDV and ESV) were significantly reduced. Systemic vascular resistance (SVR), isovolumetric relaxation time (Tau), and oxygen content in arterial and mixed venous blood increased significantly. LV end diastolic pressure (EDP) remained constant. After rewarming all the above mentioned hemodynamic variables that were depressed during $25^{\circ} \mathrm{C}$ remained reduced, except for $\mathrm{CO}$ that returned to pre-hypothermic values due to an increase in heart rate. Likewise, SVR and EDP were significantly reduced after rewarming, while Tau, EDV, ESV and blood oxygen content normalized. Serum levels of cardiac troponin $T(T n T)$ and tumor necrosis factor-alpha (TNF- $\alpha$ ) were significantly increased.

Conclusions: Progressive cooling to $25^{\circ} \mathrm{C}$ followed by rewarming resulted in a reduced systolic, but not diastolic left ventricular function. The post-hypothermic increase in heart rate and the reduced systemic vascular resistance are interpreted as adaptive measures by the organism to compensate for a hypothermia-induced mild left ventricular cardiac failure. A post-hypothermic increase in TnT indicates that hypothermia/rewarming may cause degradation of cardiac tissue. There were no signs of inadequate global oxygenation throughout the experiments.
\end{abstract}

\section{Introduction}

Physicians must take care of patients exposed to various types and levels of hypothermia. In severe accidental hypothermia, surviving victims may have an excellent prognosis, even in the most serious cases of hypothermic circulatory arrest $[1,2]$. Still, even if spontaneous circulation is maintained at moderate $\left(30\right.$ to $\left.34^{\circ} \mathrm{C}\right)$ or severe (below $30^{\circ} \mathrm{C}$ ) body temperature [3] during accidental hypothermia, victims may present with impaired cardiovascular function. While the occurrence of life threatening cardiac arrhythmias usually subside

\footnotetext{
* Correspondence: ole.magnus.filseth@unn.no

'Department of Anesthesiology, Institute of Clinical Medicine, University of Tromsø, N-9037 Tromsø, Norway

Full list of author information is available at the end of the article
}

with increasing core temperature [4], hypotension and low cardiac output may prevail during and after rewarming $[5,6]$.

On the other hand, in the context of induced moderate hypothermia being applied as a protective measure during cardiac surgery, or as a therapeutic action to mitigate global brain ischemic injury in survivors after cardiac arrest, cardiovascular side effects from hypothermia seldom cause problems [7].

In awake homoeothermic animals exposure to cold that may lower body temperature is stressful and will lead to strong neuroendocrine activation and an increase in heart rate and blood pressure [8]. There is experimental evidence that this stress reaction may eliminate the positive effects achieved by applying therapeutic

\section{Biomed Central}


hypothermia $[9,10]$. As a recognition that it is the combined effect of sedation/anesthesia and hypothermia that favors both the central nervous and the cardiovascular system after cardiac arrest, deep sedation is now an integral part of therapeutic hypothermia protocols [7]. This is in accordance with clinical observations that surviving victims of accidental hypothermia influenced by sedative drugs or ethanol tolerate hypothermia and rewarming better than victims unaffected by these substances $[6,11]$.

From experimental hypothermia research results have been somewhat confounding regarding the effect of low body temperature per se on myocardial function. From studies on isolated dog and rabbit hearts subjected to moderate and severe hypothermia, increased left ventricular (LV) contractility and increased cardiac work have been reported $[12,13]$. Core cooling to $33^{\circ} \mathrm{C}$ in a pig model mimicking therapeutic hypothermia suggested improved systolic, but depressed diastolic function [14]; similar results were found in surface cooled dogs [15]. In severe hypothermia, increased LV contractile force was demonstrated in intact dogs during surface cooling to 20 to $25^{\circ} \mathrm{C}$ [16]. Likewise, immature swine cooled by extracorporeal circuit peaked in LV stroke volume and work at $29^{\circ} \mathrm{C}$ [17]. On the other hand, intact dogs that were core cooled to $25^{\circ} \mathrm{C}$ and rewarmed showed reduced myocardial contractility during as well as after hypothermia [18]. The issue of differences in physiologic effects between species was demonstrated in a recent comparative study using cardiac tissue from humans and rabbits that revealed reduced inotropy by moderate hypothermia in human as opposed to rabbit [19]. The findings were related to differences in myocardial tissue sarcoplasmic reticulum $\mathrm{Ca}^{2+}$ storage and $\mathrm{Ca}^{2+}$ sensitivity [19].

The cooling mechanism in out-of-hospital accidental hypothermia is by surface cooling, and this approach has also been used to induce therapeutic hypothermia in survivors after cardiac arrest even though core cooling by indwelling vascular catheters has been developed and used over the last years [7]. Rewarming in therapeutic hypothermia is passive or by active external warming. As for victims of accidental hypothermia with a perfusing rhythm, the American Heart Association recommends the use of active external rewarming in moderate hypothermia and core rewarming in severe hypothermia [3]. However, surface rewarming by forced air has been proven to be safe and successful even in victims of severe hypothermia considered having a perfusing rhythm [20].

To our knowledge, no clinical studies have so far described the complete time-course of surface cooling, steady-state hypothermia and surface rewarming on cardiovascular function and other clinically related physiologic variables in either accidental or therapeutic hypothermia.

Previous experimental hypothermia studies of surface cooling/rewarming in animals with maintained circulation have been performed using rodents [21] and dogs $[22,23]$. However, in these species cardiovascular function seem to react differently to changes in temperature as rodents increase their stroke volume (SV) during severe hypothermia $[24,25]$, whereas in dogs SV remains unchanged at this temperature zone and an elevated systemic vascular resistance (SVR) is maintained after rewarming even from prolonged surface hypothermia $[22,23]$.

The apparently closer morphologic and physiologic relationship between humans and pigs suggests that a porcine model is more suitable for translational research. We aimed at developing a pig model of hypothermia and rewarming that should be minimally invasive, but give maximum information of cardiovascular function. Paramount in this effort would be the use of an indwelling conductance catheter in the left ventricle to extract pressure-volume and contractility data.

Considering animal welfare, we aimed at sedating the pigs deeply, bringing the model close to therapeutic hypothermia as used in human medicine. By avoiding the use of neuromuscular blockers, and by cooling the animals to severe hypothermia, we intended to shed light on aspects of accidental hypothermia as well.

The present study reports that hypothermia below $34^{\circ} \mathrm{C}$ reduced cardiac contractile functional variables (PRSW and $\left.\mathrm{dP} / \mathrm{dt}_{\max }\right)$ significantly, and that the depressed cardiac function prevailed during rewarming. We demonstrated that post-hypothermic contractile dysfunction is due to an isolated perturbation of systolic function, whereas diastolic function is restored.

\section{Material and methods \\ Animals}

Twelve castrated male juvenile pigs (weight 24 to $36 \mathrm{~kg}$ ) from a native Norwegian stock (norsk landsvin) were used, of whom eight animals were cooled and rewarmed and four animals were kept normothermic as timematched controls. The animals received humane care in accordance with The Norwegian Animal Welfare Act. The study was approved by The National Animal Research Authority.

The animals were placed in pens for two to five days after arrival to the laboratory animal unit. They were fed twice daily and had free access to water at all times.

\section{Experimental protocol}

The overall protocol layout is visualized in Figure 1. Following instrumentation and a one-hour rest, baseline recordings were done, and dopamine infusions at 4,8 


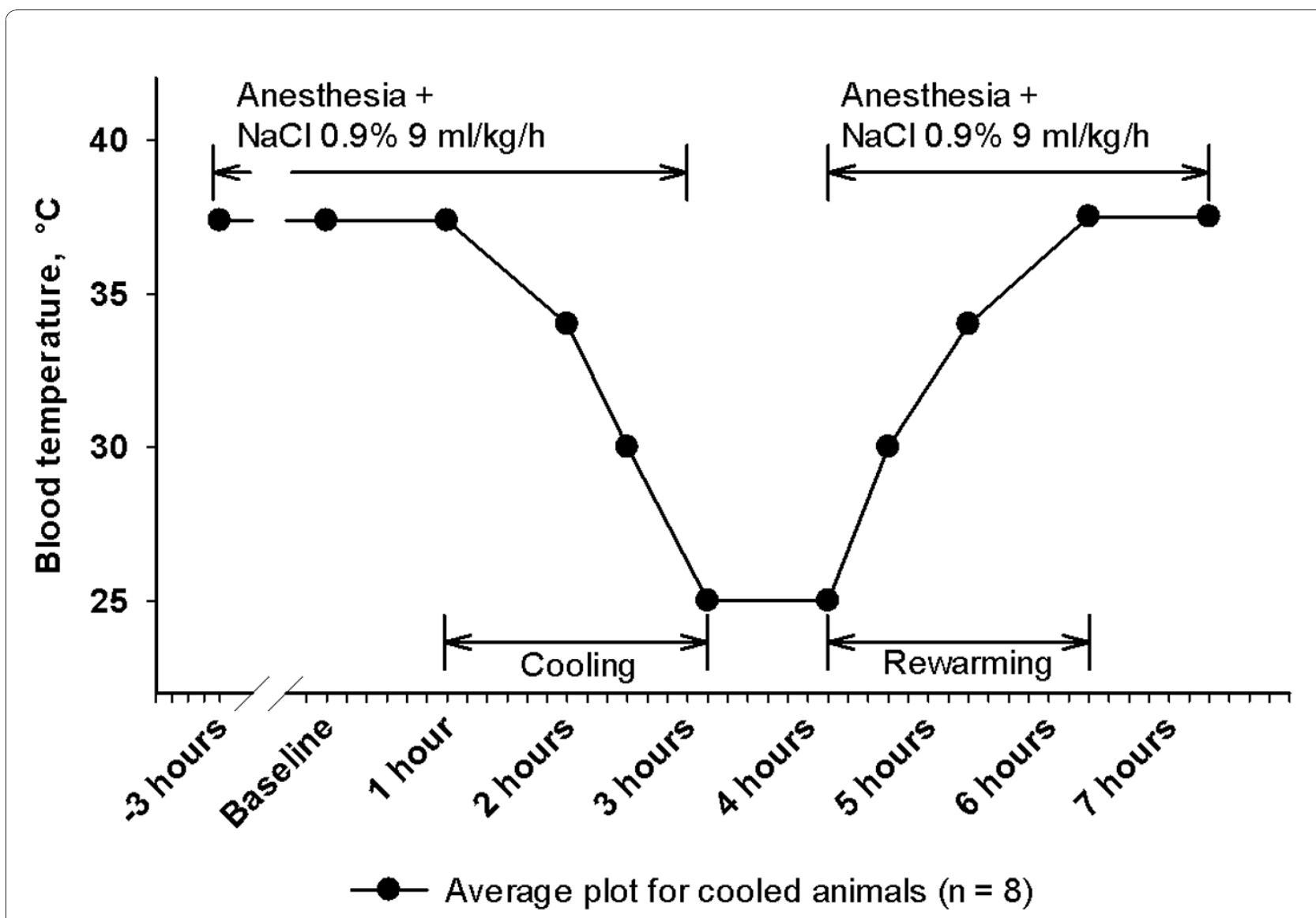

Figure 1 Protocol layout.

and $16 \mu \mathrm{g} / \mathrm{kg} /$ minute in steps of 15 minutes duration were subsequently started in all animals. The reason for this was that the eight animals subjected to cooling were to serve as controls in another study testing the effects of dopamine during normothermia, severe hypothermia and rewarming. After the dopamine infusion was stopped, the eight animals in the study group were immersion cooled to a core temperature of $25^{\circ} \mathrm{C}$. After one hour at this temperature they were rewarmed in warm water to a core temperature of $38^{\circ} \mathrm{C}$.

\section{Anesthesia and instrumentation}

After an overnight fast, anesthesia was induced in the pen by an intramuscular bolus of ketamine hydrochloride $20 \mathrm{mg} / \mathrm{kg}$, midazolam $25 \mathrm{mg}$ and atropine $1.0 \mathrm{mg}$. After transfer to the animal research operating theatre, a catheter was inserted into an ear vein and a bolus injection of fentanyl $10 \mu \mathrm{g} / \mathrm{kg}$ and pentobarbital-sodium $10 \mathrm{mg} / \mathrm{kg}$ was given. After tracheostomy a continuous right external jugular vein infusion of fentanyl $20 \mu \mathrm{g} /$ $\mathrm{kg} / \mathrm{h}$, pentobarbital-sodium $4 \mathrm{mg} / \mathrm{kg} / \mathrm{h}$ and midazolam $0.3 \mathrm{mg} / \mathrm{kg} / \mathrm{h}$ along with Ringer's acetate $9 \mathrm{ml} / \mathrm{kg} / \mathrm{h}$ was started and maintained throughout the experiment, except for the one-hour period at $25^{\circ} \mathrm{C}$ core temperature. After termination of experiments the animals were killed with $20 \mathrm{mmol}$ potassium chloride given as an intravenous bolus. No neuromuscular blockers were used at any time. Animals were maintained on intermittent positive pressure ventilation and a positive end expiratory pressure (PEEP) of $4 \mathrm{~cm} \mathrm{H}_{2} \mathrm{O}$ was applied throughout the experiments (Siemens Servo 900 D, Solna, Sweden). $\mathrm{FiO}_{2}$ was adjusted to maintain $\mathrm{PaO}_{2}>$ $10 \mathrm{kPa}$, and alveolar ventilation adjusted to keep $\mathrm{PaCO}_{2}$ of 4.5 to $6 \mathrm{kPa}$ uncorrected for temperature ( $\alpha$-stat management). Arterial pressure monitoring and blood sampling were obtained via a femoral artery catheter. A 5F thermodilution catheter (Edwards Lifesciences, Irvine, CA, USA) was positioned in the pulmonary artery via the right external jugular vein for pressure monitoring, continuous core temperature recording, cardiac output measurements and for blood sampling. A single dose of 3,000 IU heparin was given after placement of the thermodilution catheter. Via the left carotid artery a $7 \mathrm{~F}$ dual field, pressure-volume conductance catheter (CD Leycom, Zoetermeer, The Netherlands) was positioned in the left cardiac ventricle for 
continuous pressure and volume monitoring. To obtain intermittent preload reductions a 7F balloon catheter was positioned in the inferior caval vein via the left femoral vein. A $14 \mathrm{~F}$ urinary bladder catheter was introduced via a lower abdominal incision for continuous monitoring of urinary output.

\section{Data sampling}

Each data sampling procedure lasted about five minutes and was carried out in the following order: 1) acquisition of electrocardiography (ECG), mean arterial blood pressure (MAP) and central venous pressure (CVP); 2) recording of cardiac output (CO), blood temperature, diuresis and respirator settings; 3 ) blood sampling from femoral and pulmonary arteries; 4) recording of steady state LV pressure-volume (PV) data, and; 5) recording of PV data during inferior vena cava occlusions. Data sets were collected at baseline, during cooling at core temperatures 34,30 and $25^{\circ} \mathrm{C}$, during maintained hypothermia $\left(25^{\circ} \mathrm{C}\right)$ and during rewarming at 30,34 and $38^{\circ} \mathrm{C}$.

\section{Conductance catheter methods}

The conductance catheter placement was guided by LV pressure signals being displayed on a monitor and by advancing the catheter to obtain the maximum number of segments displaying ventricular volumes without causing ventricular arrhythmias. Segments lying outside the ventricle were excluded before each recording. Steady state recordings of PV-loops were performed with the respirator attached. LV contractility at each temperature was determined as the mean value derived from three successive caval occlusions and PV-loop recordings, each time disconnecting the respirator for about $10 \mathrm{sec}$, and successive respirator attachment and recovery of MAP between occlusions. Data were continuously computed and stored on a Leycom Sigma 5 DF computer (CardioDynamics, San Diego, CA, USA) and later analysed by Circlab software (GTX Medical Software, Zoetermeer, The Netherlands). In analysis, conductance derived $\mathrm{CO}$ was corrected against $\mathrm{CO}$ measured by thermodilution measurements of cardiac output by a thermodilution computer (Vigilance, Edwards Lifesciences, Irvine, CA, USA) at each temperature step. In this way, there was no need to correct for temperature dependent blood resistivity (rho), as the thermodilution method is independent from conductance catheter recordings and unaffected by rho. During sampling rho was arbitrarily set at the same fixed value on the Leycom Sigma 5 DF computer at all temperatures.

The conductance derived LV end diastolic and systolic volumes (EDV and ESV) resulted from intraventricular conductance and the conductance of surrounding structures, called parallel conductance. Parallel conductance determination by use of repetitive hypertonic (30\%) saline infusions at each temperature was not performed, as this would have lead to considerable $\mathrm{NaCl}$ accumulation throughout the experiment. Consequently, EDV and ESV in this study do not represent real LV volumes, and no measure of LV ejection fraction could be calculated. However, recording of relative LV volume changes during cooling and rewarming could be performed.

Steady state readings of conductance data gave, in addition to $L V$ volumes, maximum and minimum values of the first derivate of ventricular pressure over time $\left(\mathrm{dP} / \mathrm{dt}_{\max }, \mathrm{dP} / \mathrm{dt}_{\text {min }}\right)$, the time constant of isovolumetric relaxation (Tau) based on a monoexponential decay model and LV end diastolic and systolic pressures (EDP and ESP). Preload recruitable stroke work (PRSW), end systolic elastance $\left(E_{\text {es }}\right)$ and end diastolic pressure volume relationship (EDPRV) were calculated based on PV recordings during abrupt inferior vena cava occlusions. $V_{0}$ was defined by the intercept of the $E_{e s}$ slope of the $\mathrm{x}$-axis (volume axis).

Arterial elastance $\left(E_{a}\right)$ was calculated as $E_{a}=$ LVESP/ stroke volume (SV). Arterial-ventricular coupling ratio was determined by $\mathrm{E}_{\mathrm{a}} / \mathrm{E}_{\mathrm{es}}$.

At core temperatures below $30^{\circ} \mathrm{C}$ inferior caval occlusions did not induce changes in PV loops that could be applied to calculate PRSW, EDPVR or $\mathrm{E}_{\mathrm{es}}$, probably because the heart obtained most of its filling from the superior caval vein at this low-flow state.

\section{Recording and calculation of hemodynamic variables}

ECG from standard leads, heart rate (HR), CVP, MAP, and PAP were continuously displayed on a data monitor and intermittently recorded by a computer program designed at our department using the software package LabVIEW тм v.6.1 (National Instruments, Austin, TX, USA). At pre-determined temperatures $\mathrm{CO}$ was measured in triplets, by injecting $5 \mathrm{ml}$ precooled saline in the thermodilution catheter positioned in the pulmonary artery. SV and systemic vascular resistance (SVR) were calculated as: $\mathrm{SV}=\mathrm{CO} / \mathrm{HR} ; \mathrm{SVR}=(\mathrm{MAP}-\mathrm{CVP}) \cdot 80 /$ CO. To index SVR body surface area (BSA) was calculated according to the formula: BSA in $\mathrm{m}^{2}=(734$ .Weight $\left.{ }^{0.656}\right)$ : 10,000 [26].

Global delivery and consumption of oxygen $\left(\mathrm{DO}_{2}\right.$ and $\mathrm{VO}_{2}$ ) were calculated as oxygen content in arterial blood . CO, and the difference of arterial and mixed venous oxygen content $\mathrm{CO}$, respectively.

\section{Immersion cooling and rewarming}

After instrumentation all surgical wounds were sutured in two layers and the animals were laid in a right lateral recumbent position on the operating table. By use of a centrifugal pump (Bio-Medicus, Eden Prairie, MN, USA), and a heat-exchanger (Stöckert Normo/hypothermie, 
Munich, Germany), cold water $\left(5^{\circ} \mathrm{C}\right)$ circulated the hollow operating table and a tarpaulin tub surrounding the animal. The upper left side of the animal was covered with ice slush and irrigated by cold water leaving twothirds of the dependent animal submerged. The head was placed on a cushion and not immersed or covered with ice slush. At $26^{\circ} \mathrm{C}$ core temperature cold water circulation was discontinued, the tub drained for water and ice slush, and core temperature subsequently dropped to approximately $25^{\circ} \mathrm{C}$ in all animals. To prevent core temperature from a further drop, small amounts of warm water was added to the tub. Rewarming was achieved by circulating the operating table and the tub, and by irrigating the upper left side of the animal, with hot water ( 40 to $42^{\circ} \mathrm{C}$, measured in the afferent water hose) till rewarming $\left(38^{\circ} \mathrm{C}\right)$ was accomplished.

\section{Biochemical analyses Catecholamines}

Blood with heparin $(4 \mathrm{IU} / \mathrm{ml})$, reduced glutathione $(4.5$ $\mathrm{mM})$ and EGTA (5 $\mathrm{mM})$ was kept on ice/water for maximally 30 minutes before plasma was obtained by centrifugation $(1.000 \times \mathrm{g})$ for 20 minutes at $4^{\circ} \mathrm{C}$. Samples were stored at $-80^{\circ} \mathrm{C}$ awaiting analysis.

Plasma samples ( 1 to $2 \mathrm{ml}$ ) were spiked with known concentrations of the internal standard (DHBA $=$ dihydroxy-benzylamine) and added $1 \mathrm{ml} 2 \mathrm{M}$ Tris-EDTA buffer ( $\mathrm{pH}$ 8.7). The catecholamines were adsorbed onto alumina $(10 \mathrm{mg})$. After aspiration of plasma/buffer, the alumina was washed three times with bi-distilled water $(1 \mathrm{ml})$. The catecholamines were eluted from the alumina with a mixture $(100 \mu \mathrm{l})$ comprising acetic acid (175 $\mathrm{mM})$, sodium bisulfide $(9 \mathrm{mM})$ and EDTA (0.7 $\mathrm{mM})$. After whirling and centrifugation, the aquous phase was aspirated and transferred to the autoinjector (Dionex ASV-100, Dionex, Sunnyvale, CA, USA).

Dopamine, norepinephrine and epinephrine were separated by HPLC (Dionex P680, Dionex ASV-100, Dionex, Sunnyvale, CA, USA; Chromsystems analytical column and eluent, Chromsystems Instruments\&Chemicals $\mathrm{GmbH}$, Munich, Germany) and their concentrations determined with an electrochemical detector (ESA Coulochem, III, ESA, Chelmsford, MA, USA). The analyses were performed at ambient temperature with a flow of $1.2 \mathrm{ml} / \mathrm{ml}$.

\section{Other analyses}

Hemoglobin $(\mathrm{Hb})$ measurements, and arterial and mixed venous blood gases were analysed on a blood gas analyser (Rapid lab, Chiron Diagnostics, Emeryville, CA, USA) uncorrected for temperature. Blood samples for serum analysis were put on ice, quickly centrifuged and the serum was then quickly frozen and kept at $-80^{\circ} \mathrm{C}$ awaiting analysis. Tumor necrosis factor alpha (TNF- $\alpha$ ) was analysed by the quantitative sandwich enzyme immunoassay technique (Quantikine ${ }^{\ominus}, \mathrm{R} \& D$ Systems, Inc., Minneapolis, MN, USA). Troponin T (TnT), ASAT, ALAT and albumin were analysed by the sandwich method of electrochemiluminescence, UV-test with pyridoxal phosphate activation, and a colorimetric end point method (Modular, Roche Diagnostics, Rotkreuz, Switzerland).

\section{Statistical analyses}

Statistical analyses were performed using SigmaPlot statistical software version 9 - 11 (Systat Software Inc. (SSI), Richmond, CA, USA). Intragroup comparisons were performed by one-way repeated measures analysis of variance, or by paired sample Student's $t$ test when only single comparisons were made. For comparisons between groups, the Student's $t$ test was used if data showed normal distribution, otherwise the Mann-Whitney rank sum test was used. Level of significance was set at $P \leq 0.05$. Data are presented as mean \pm SEM. Statistically significant changes are referred to as simply significant changes for the sake of convenience.

\section{Results}

\section{Cooling and rewarming observations}

Immersion cooling to $25^{\circ} \mathrm{C}$ lasted $125 \pm 15$ minutes giving a cooling rate of $6.8 \pm 0.7^{\circ} \mathrm{C} / \mathrm{h}$. Rewarming lasted 133 \pm 6 minutes, giving a rewarming rate of $6.0 \pm 0.3^{\circ} \mathrm{C} / \mathrm{h}$. The phenomenon referred to as 'afterdrop', a decrease in core temperature after onset of surface warming, was not observed in any pigs. Visible shivering took place in all pigs at the start of cooling, but subsided with progressive cooling and was absent at $25^{\circ} \mathrm{C}$. Little, if any, shivering was observed during and after rewarming.

\section{Effects of cooling, steady state severe hypothermia, and rewarming on cardiovascular function Mild hypothermia}

$\mathrm{E}_{\mathrm{es}}$ (Figure $2 \mathrm{~B}$ ) as the sole indicator of LV contractility, increased significantly at $34^{\circ} \mathrm{C}$, as did indexes of diastolic function, Tau (Figure 3D) and EDPVR (Figure 3C). dP/ $\mathrm{dt}_{\text {min }}$ (Figure $3 \mathrm{~A}$ ) decreased significantly (maximal deceleration decreased). MAP (Figure $4 D$ ) and $E_{a} / E_{e s}$ (Figure $3 \mathrm{C})$ decreased significantly at $34^{\circ} \mathrm{C}$. All other hemodynamic variables were statistically unaffected by cooling to $34^{\circ} \mathrm{C}$.

\section{Cooling below $34^{\circ} \mathrm{C}$}

Indexes of LV contractility PRSW (Figure 2A) and dP/ $\mathrm{dt}_{\max }$ (Figure 2D) decreased significantly during cooling below $34^{\circ} \mathrm{C}$, while $\mathrm{E}_{\text {es }}$ and $\mathrm{E}_{\mathrm{a}} / \mathrm{E}_{\text {es }}$ (Figure $2 \mathrm{C}$ ) were statistically unaffected. $\mathrm{V}_{0}$ (not shown) was statistically indifferent to moderate and severe cooling, as were EDP (Figure 3B) and EDPVR. EDV, ESV (Figure 4F) and CVP (not shown) decreased during cooling, reaching statistical significance at $25^{\circ} \mathrm{C} \cdot \mathrm{dP} / \mathrm{dt}_{\text {min }}$ was statistically 

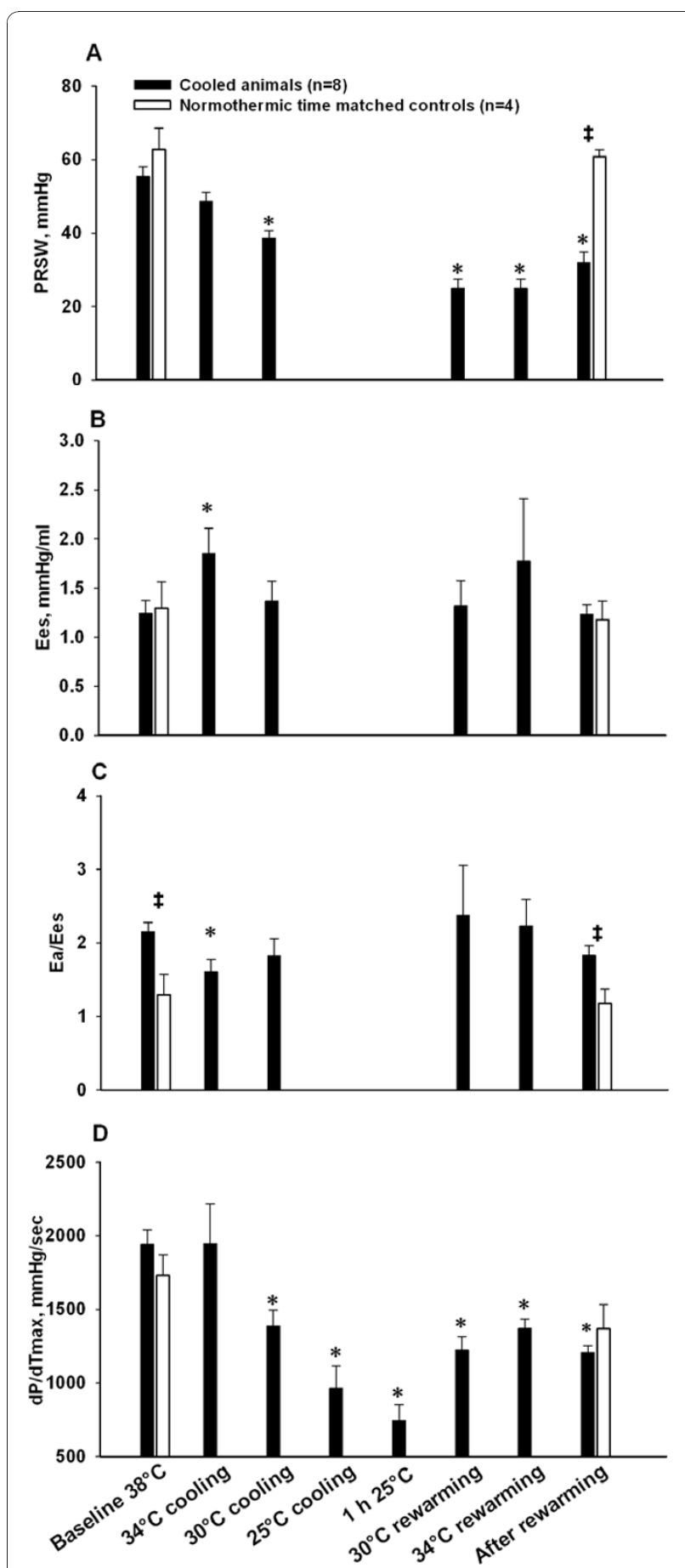

Figure $\mathbf{2}$ Left ventricular contractility data. A. Preload recruitable stroke work (PRSW); B. end systolic elastance $\left(E_{e s}\right)$; C. arterialventricular coupling ratio $\left(E_{a} / E_{e s}\right) ; \mathbf{D}$. maximal acceleration of pressure in the cardiac cycle $\left(\mathrm{dP} / \mathrm{dt}_{\max }\right)$. *Significantly different from baseline $(P \leq 0.05)$. \# Significant difference between cooled animals and time matched normothermic controls $(P \leq 0.05)$.
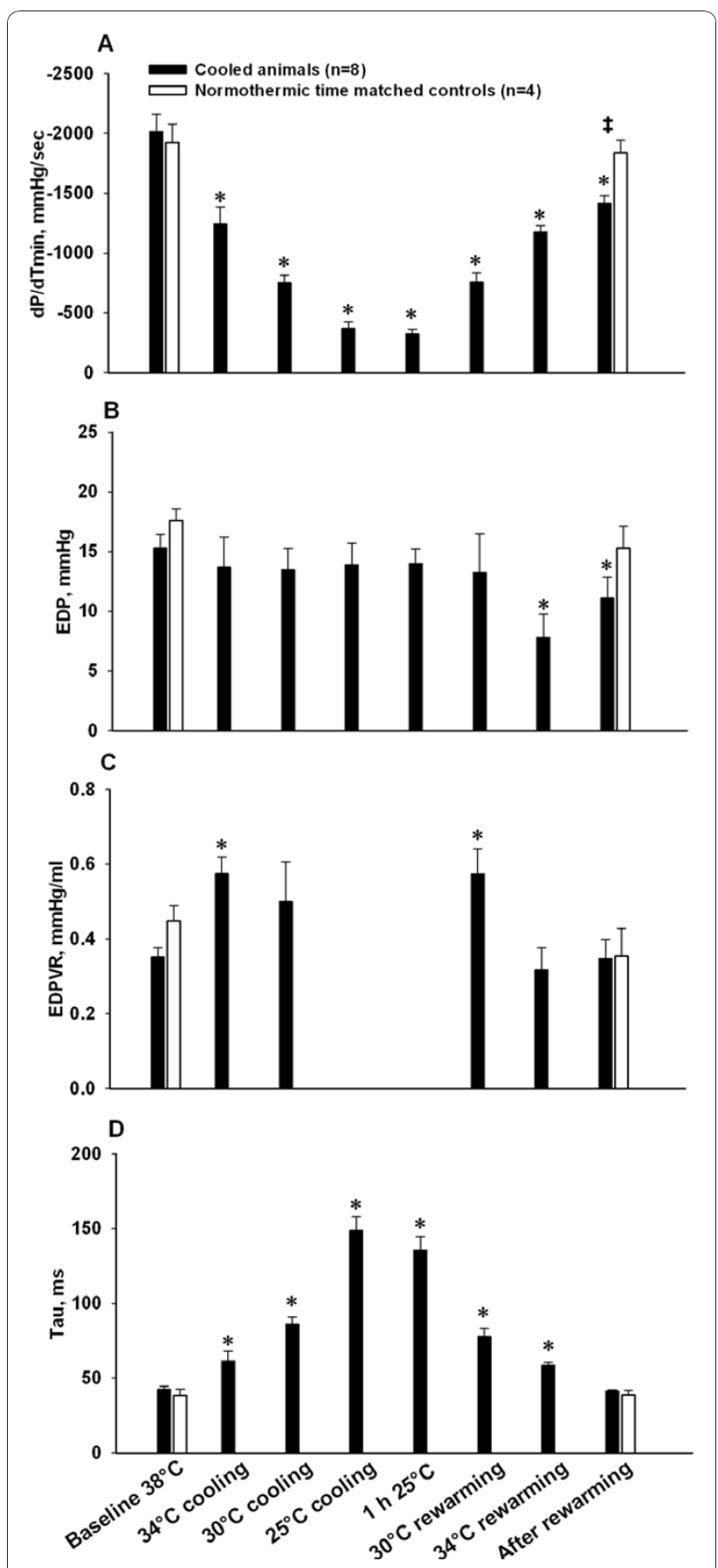

Figure 3 Indexes of left ventricular diastolic function. A Maximal deceleration of pressure in the cardiac cycle $\left(\mathrm{dP} / \mathrm{dt}_{\mathrm{min}}\right) ; \mathbf{B}$. end diastolic pressure (EDP); $\mathbf{C}$. end diastolic pressure volume relationship (EDPVR); D. isovolumetric relaxation time (Tau). *Significantly different from baseline $(P \leq 0.05)$. ₹ Significant difference between cooled animals and time matched normothermic controls $(P \leq 0.05)$. 

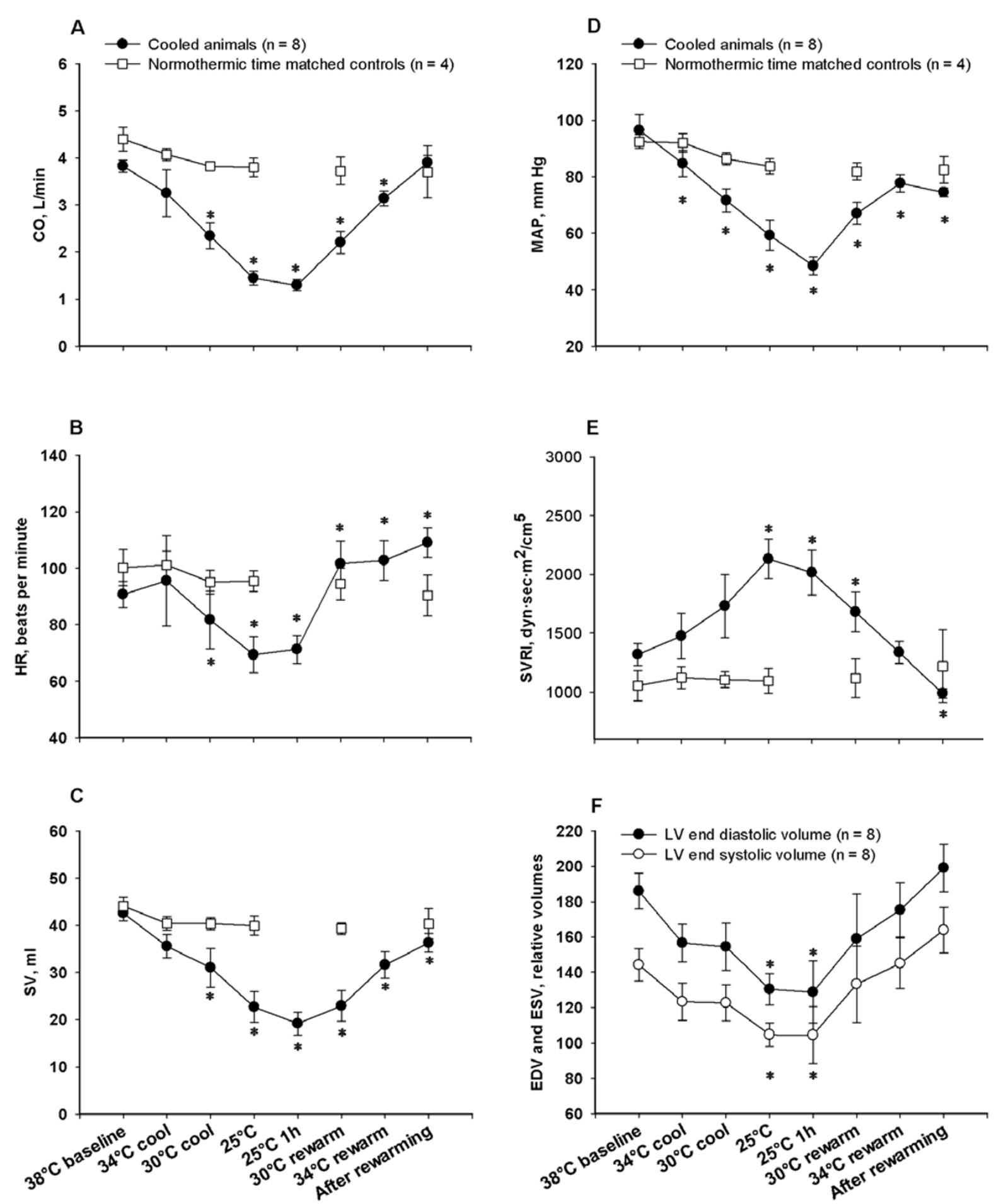

Figure 4 General hemodynamic recordings. A. Cardiac output (CO); B. heart rate (HR); C. stroke volume (SV); D. mean arterial pressure (MAP); E. systemic vascular resistance index (SVRI); $\mathbf{F}$. end diastolic and systolic volumes (EDV and ESV). *Significantly different from baseline $(P \leq 0.05)$.

reduced in a linear pattern during cooling, whereas Tau increased in a pattern reciprocal to the $\mathrm{dP} / \mathrm{dt}_{\min }$ curve.

CO (Figure 4A), HR (Figure 4B), SV (Figure 4C), and MAP all decreased significantly in a linear way below $34^{\circ} \mathrm{C}$. SVRI (Figure $4 \mathrm{E}$ ) increased in a nearly similar pattern, reaching significance at $25^{\circ} \mathrm{C}$. Except for coldinduced bradycardia, no arrhythmias were encountered until severe hypothermia was established. 
One hour steady state hypothermia at $25^{\circ} \mathrm{C}$

No PV data derived from inferior caval occlusions were available at this temperature. Values for $\mathrm{dP} / \mathrm{dt}_{\max }, \mathrm{dP} /$ $\mathrm{dt}_{\text {min }}, \mathrm{CO}, \mathrm{SV}$ and $\mathrm{HR}$ reached their nadir during the 1 $\mathrm{h}$ period at $25^{\circ} \mathrm{C}$, while Tau reached its highest value, as did SVRI.

During stable severe hypothermia sinus bradycardia and various idioventricular arrhythmias were seen. The ECG did not show atrial fibrillation nor the so called Jwave or Osborn wave, both characteristics of severe hypothermia in humans [27] in any pig. In four out of eight pigs the phenomenon of mechanical (or pulsus) alternans [28] occurred; that is, a reduced stroke volume observed on the conductance monitor every other heart beat in the absence of corresponding abnormalities in the ECG. One animal got ventricular fibrillation (VF) that was successfully defibrillated to an organized rhythm during the one-hour period at $25^{\circ} \mathrm{C}$.

\section{Rewarming and post-hypothermic results}

During rewarming PRSW and $\mathrm{dP} / \mathrm{dt}_{\max }$ were significantly lowered when compared to corresponding temperatures during cooling. HR made an abrupt and significant increase during rewarming from 25 to $30^{\circ} \mathrm{C}$, and remained significantly elevated at a stable level above this temperature. The other variables that were reduced by cooling tended to approach corresponding values during rewarming in a nearly mirror image pattern.

After rewarming PRSW, $\mathrm{dP} / \mathrm{dt}_{\max }, \mathrm{dP} / \mathrm{dt}_{\min }, \mathrm{SV}$, MAP, EDP and SVRI remained significantly decreased compared to pre-hypothermic baseline values. CVP, EDV and ESV returned to pre-hypothermic controls. While post-hypothermic $\mathrm{E}_{\mathrm{es}}$ was statistically unchanged, $\mathrm{V}_{0}$ was significantly increased after rewarming.

Due to a significant increase in HR, post-hypothermic $\mathrm{CO}$ returned to within pre-hypothermic values. Tau and EDPVR, having been increased during rewarming, returned to control. In all animals cardiac rhythm spontaneously returned to sinus rhythm and mechanical alternans disappeared during rewarming.

\section{Effects of cooling, steady state severe hypothermia and} rewarming on other variables

Hemoglobin $(\mathrm{Hb})$ concentration (Figure 5A) showed a biphasic pattern, decreasing significantly during cooling and increasing significantly during severe hypothermia and rewarming. Oxygen content of arterial and mixed venous blood (not shown) followed a pattern nearly synchronous with the $\mathrm{Hb}$ curve, increasing statistically during severe hypothermia. The global delivery and consumption of oxygen $\left(\mathrm{DO}_{2}\right.$ and $\mathrm{VO}_{2}$, Figure $\left.5 \mathrm{~B}, \mathrm{C}\right)$ were reduced by
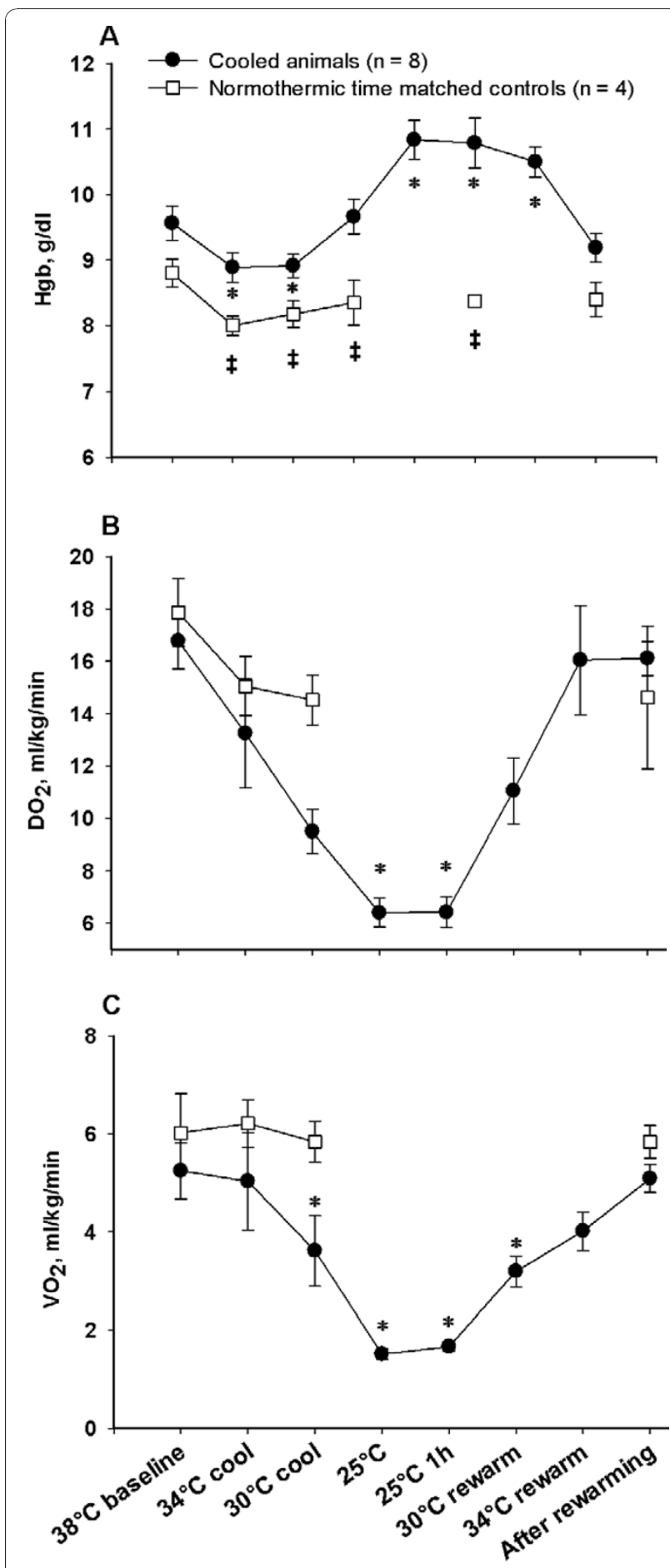

Figure 5 Oxygen variables. A. Blood hemoglobin concentration $(\mathrm{Hb})$; B. global delivery of oxygen $\left(\mathrm{DO}_{2}\right)$; $\mathbf{C}$. global consumption of oxygen $\left(\mathrm{VO}_{2}\right)$. *Significantly different from baseline $(P \leq 0.05)$. \# Significant difference between cooled animals and time matched normothermic controls $(P \leq 0.05)$ in Figure 5A. 
$61 \pm 4 \%$ and $68 \pm 6 \%$ respectively during cooling, giving corresponding reductions of $4.7 \pm 0.3 \%$ and $5.2 \pm 0.4 \%$ per degree $\mathrm{C}$. While $\mathrm{DO}_{2}$ correlated with temperature in a linear manner, the reduction in $\mathrm{VO}_{2}$ was just about $1 \%$ per degree $\mathrm{C}$ in the temperature interval between 38 and $34^{\circ} \mathrm{C}$ and about $7.8 \%$ per degree $\mathrm{C}$ from 34 to $25^{\circ} \mathrm{C}$, reflecting that the relationship between $\mathrm{VO}_{2}$ and decrease in temperature took the form of a negative exponential function. During rewarming $\mathrm{DO}_{2}$ returned to pre-hypothermic baseline values following a mirror image of the pattern during cooling, while $\mathrm{VO}_{2}$ normalized in a more linear way than during cooling. Albumin values (Figure 6A) decreased significantly during cooling and remained significantly reduced after rewarming. Significant increases in both troponin T (TnT, Figure 6B) and TNF- $\alpha$ (Figure 6C) serum concentrations were seen after rewarming, both in contrast to their own baseline values and to time matched controls. Serum concentrations of dopamine, epinephrine and nor-epinephrine (not shown) were statistically unchanged from pre-hypothermic values throughout the experiments. Diuretic output (not shown) was not affected by temperature throughout experiments.

\section{Discussion}

The present study demonstrates that severe hypothermia $\left(30\right.$ to $25^{\circ} \mathrm{C}$ ) reduced cardiac contractile functional variables (PRSW and $\mathrm{dP} / \mathrm{dt}_{\max }$ ) significantly, and that the depressed cardiac function prevailed during rewarming. After rewarming we found that post-hypothermic contractile dysfunction is due to isolated perturbation of systolic function, whereas diastolic function is restored.

Our anesthetized animals, showing no endogenous catecholamine response during cooling or rewarming, clearly differ from awake animals subjected to surface cooling [8], bringing the actual model close to the clinical hypothermia setting. As no neuromuscular blockers were administered, initial shivering during cooling, well known from accidental and clinical hypothermia [4,29], was present. Shivering occurred in spite of the apparently deep anesthetic state. This may be a species related phenomenon, as shivering in therapeutic hypothermia in man most often can be controlled with various sedative drugs [7].

\section{LV systolic function}

Data collected at $34^{\circ} \mathrm{C}$ suggest a possibly increased inotropy at this temperature, as $\mathrm{E}_{\mathrm{es}}$ was increased and $\mathrm{PRSW}$ and $\mathrm{dP} / \mathrm{dt}_{\max }$ were unaffected. Progressive cooling from $34^{\circ} \mathrm{C}$ to severe hypothermia induced a reduction in LV contractile indexes PRSW and $\mathrm{dP} / \mathrm{dt}_{\max }$, that, together with reduced SV, suggests reduced systolic function. Moreover, the significantly reduced PRSW and $\mathrm{dP} / \mathrm{dt}_{\max }$ during and after rewarming compared with corresponding temperatures before and during cooling,

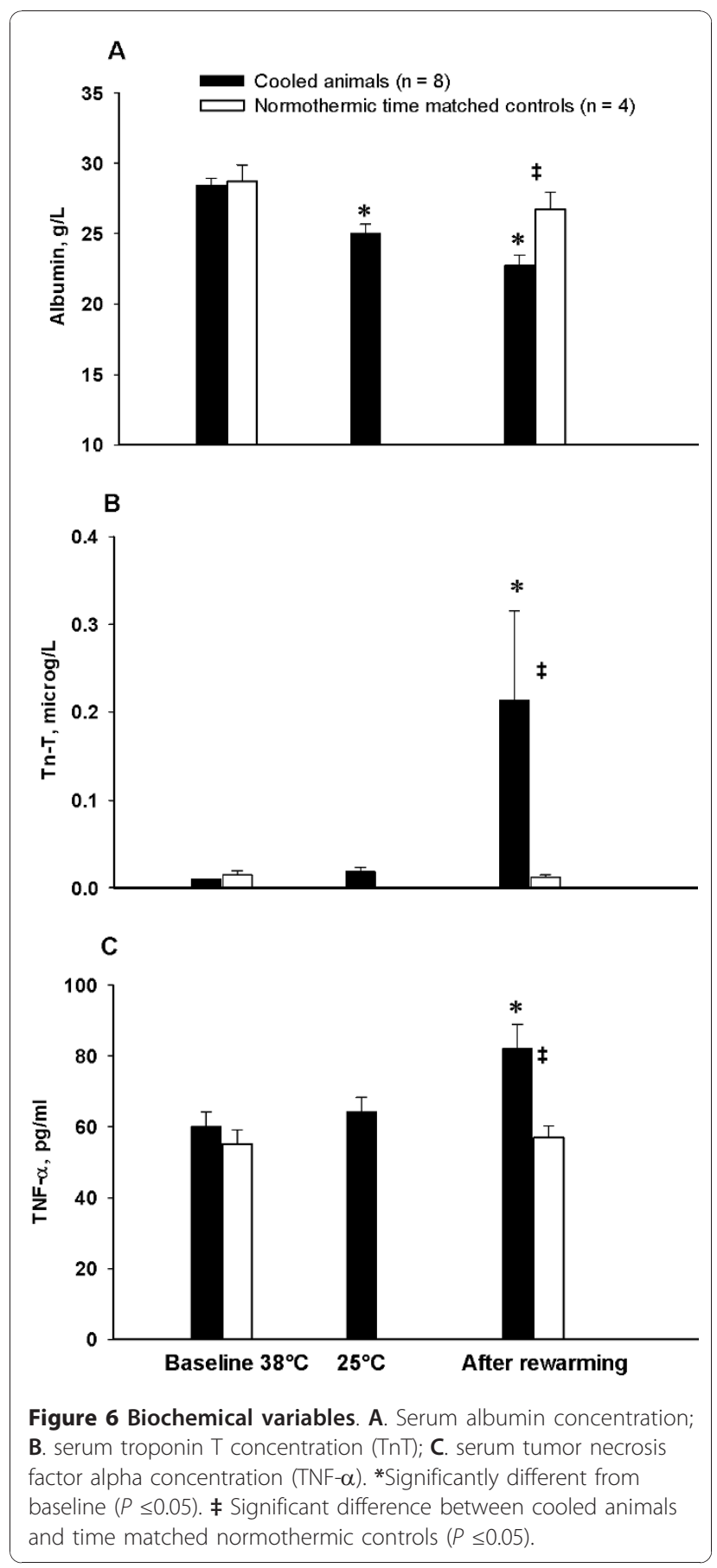

imply a reduction in LV contractility that progresses with the duration of hypothermia, and prevails after rewarming. This is in accordance with findings of increasing hypothermia-induced cardiac failure reported in rats when duration of severe hypothermia was increased from one to five hours [30] and with experimental findings that post-hypothermic mortality due to circulatory failure in dogs and rodents increased with the duration of exposure to severe hypothermia [22,31]. 
While the complete pathophysiology of hypothermiainduced cardiac failure is not known, it seems that among other factors cytosolic $\mathrm{Ca}^{2+}$ overload is involved, possibly via a temperature-dependent dysfunction of ion transport [32]. Hypothermia-induced cardiac failure shares similarities with myocardial stunning in that both conditions may involve intracellular $\mathrm{Ca}^{2+}$ overload that may partly be attributed to hypothermia-induced inhibition of the $\mathrm{Na}^{+} / \mathrm{K}^{+}$-ATPase in the sarcolemma, partly to impaired clearance of free cytosolic $\mathrm{Ca}^{2+}$. While the proposed mechanism in hypothermia is a temperaturedependent dysfunction of ion transport mechanisms, the concept of myocardial stunning is invariably linked to the ischemia-reperfusion syndrome where dysfunction of ion transport mechanisms due to lack of ATP, together with production of reactive oxygen species, causes $\mathrm{Ca}^{2+}$ overload and modification of contractile proteins [33].

The reason why $\mathrm{E}_{\mathrm{es}}$, as opposed to the other LV contractility indexes, was statistically unchanged at moderate and severe hypothermia as well as during and after rewarming is not clear. One factor making $E_{e s}$ potentially unreliable during hypothermia may be that as core temperature is reduced, the effect of caval vein occlusions diminishes, thus making ESPVR slope determination unreliable. Hypothermia-induced bradycardia contributes to fewer ESPVR points during occlusions, another factor that may affect the accuracy of the slope. Furthermore, $E_{\text {es }}$ has been proven to be an unreliable contractility index in itself in experimental heart failure, as significant increases in $E_{e s}$ were encountered in a pig model of stunning, acute ischemic and endotoxemic heart failure despite obvious other indications (significant decreases in $\mathrm{CO}, \mathrm{dP} / \mathrm{dt}_{\max }$ and MAP) of depressed myocardial function [34]. The increases in $E_{e s}$ were accompanied with significant increases in $\mathrm{V}_{0}$, which apparently resulted in steep $E_{\text {es }}$ slopes [34]. This parallels to the finding of a post-hypothermic significant increase in $V_{0}$ in the present study. In previous experiments in dogs at our laboratory aimed at determining LV cardiac contractility during cooling and rewarming it was concluded that PRSW appeared to be a more robust index of contractility than $\mathrm{E}_{\mathrm{es}}$ during hypothermia [18].

One could argue that, in the absence of VCO-derived contractility data at $25^{\circ} \mathrm{C}$, single beat estimates of contractility could have replaced traditional deloading variables. However, in vivo single beat contractility estimations in pig have been shown to be unreliable and no better than $\mathrm{dP} / \mathrm{dt}_{\max }$ in predicting LV contractility [35].

\section{LV diastolic function}

During hypothermia changes in diastolic functional variables were measured. Most prominent was the increase in indexes of isovolumetric relaxation, Tau and $\mathrm{dP} /$ $\mathrm{dt}_{\text {min }}$, indicating a temperature-dependent slowing of sarcoplasmic reticulum (SR) function that together with elevated intracellular $\mathrm{Ca}^{2+}$ concentration delayed clearance of cytosolic $\mathrm{Ca}^{2+}$. This finding corresponds well with the fact that diastolic $\mathrm{Ca}^{2+}$ extrusion depends mainly on $\mathrm{SR} \mathrm{Ca}^{2+}$ pump activity, also during hypothermia [36], and that enzyme kinetics of the $\mathrm{Ca}^{2+}$ pump is highly temperature dependent $\left(\mathrm{Q}_{10}\right.$ effect). The passive, late diastolic phase, the filling phase, was less compromised during hypothermia as indicated by a modest increase in EDPVR, or stiffness, in the present experiment. The effects of change in temperature on the SR $\mathrm{Ca}^{2+}$ pump are demonstrated by the return to control of Tau after rewarming.

The post-hypothermic reduction of $\mathrm{dP} / \mathrm{dt}_{\min }$ (reduction in maximal deceleration) may imply an early diastolic dysfunction which remained from the hypothermic period. However, Tau and EDPVR returned to pre-hypothermic levels, EDV was statistically unchanged and EDP was even reduced after rewarming. We interpret the posthypothermic increase in $\mathrm{dP} / \mathrm{dt}_{\min }$ as resulting from the concomitantly decreased MAP, and suggest that posthypothermic early, as well as late, diastolic function is normalized after rewarming. This is in accordance with previous findings that diastolic function was restored in post-hypothermic core cooled dogs [18] and rats [24].

If the post-hypothermic state is characterized by systolic failure with maintained diastolic function, this clearly makes post-hypothermic cardiac dysfunction different from myocardial stunning, where not only systolic, but also diastolic dysfunction is an invariable finding [37].

\section{Heart rate}

Increasing HR from 80 to 120 /minute by pacing in normothermic humans before hypothermic coronary bypass grafting increased LV contractility [38]. When the same procedure was repeated during cardio-pulmonary bypass at $33^{\circ} \mathrm{C}$, pacing led to decreased contractility [38]. Also the increase in LV contractility seen when cooling of rabbit hearts in vitro was lost when normothermic HR was maintained by pacing during hypothermia [13]. Thus, an artificial increase in HR during hypothermia may be detrimental to LV contractility. In the present study, we measured an abrupt increase in HR from 25 to $30^{\circ} \mathrm{C}$ during rewarming. At this time point, PRSW was significantly lower than at $30^{\circ} \mathrm{C}$ during cooling. This raises the question; did the abrupt increase in HR cause a concomitant reduction of PRSW, or was the increase in HR a spontaneous compensatory reflex aimed at elevating cardiac contractility? As discussed above, our data support the understanding that the duration of severe hypothermia per se leads to decreased LV contractility, and we interpret the increase in HR as a compensatory mechanism whereby the organism normalized 
$\mathrm{CO}$ and $\mathrm{DO}_{2}$ in the presence of a decreased SV. According to Opie (1998), 'LV failure exists (...) when myocardial ejection is impaired because the inotropic state is depressed' [39]. Hypothermia-induced cardiac dysfunction may be perceived as a variant of acute LV failure. Clinically, increased heart rate is a common sign in acute heart failure [40], as a consequence of increased sympathetic activity to compensate for LV failure [39]. Experimentally, statistically significant elevation of plasma catecholamines is associated with pathologic reduction of myocardial contractility [41]. In the present study, however, there was no detectable increase in plasma catecholamine levels. It may still be that receptors in the heart, aortic arch and carotid sinus triggered by decreased pressure and/or flow activated brain stem neurons, leading to efferent nervous stimulation of the sinoatrial node, materialized in the present experiment by a significant increase in HR.

\section{Vascular tone}

The post-hypothermic reductions of MAP and SVR open for at least two possible interpretations; either i) we see a variant of the somewhat imprecise term 'rewarming shock', characterized by reduced cardiac function and drop in blood pressure [42], or ii) the reduced SVR is an adaptation to the reduced myocardial contractility.

In recent years, an integrated view of the interaction between vascular tone and cardiac contractility has been pursued through the study of the coupling between arterial and cardiac elastance, expressed as the $E_{a} / E_{e s}$ coupling ratio [43]. $E_{a}$ in itself, being the ratio between LVESP/SV, is not a variable solely derived from the vascular system, and as such does encompass more than SVR. Effective coupling of heart to artery may be defined as the optimal transfer of blood from heart to periphery without excessive changes in blood pressure, and it has been reported that an $E_{a} / E_{\text {es }}$ coupling ratio of 0.6 to 1.2 represents a near optimal relation between work and efficiency [44]. When systolic heart failure (low $E_{\text {es }}$ ) is accompanied by high arterial elastance (high $\left.E_{a}\right)$, the $E_{a} / E_{e s}$ is elevated and the unfavorable situation of afterload mismatch occurs [44]. In the present study post-hypothermic $E_{a} / E_{e s}$ was statistically unchanged from baseline. If MAP and SVR had remained unchanged from pre-hypothermic values, $E_{a}$ would have been increased, possibly leading to an $E_{a} / E_{e s}$ ratio significantly increased in an unfavorable direction. In our opinion the reduced post-hypothermic SVR, in the presence of reduced LV contractility and SV, does not necessarily express 'rewarming shock', but may imply an optimized arterial-ventricular coupling ratio that together with increased HR facilitates more physiologic $\mathrm{CO}$ and $\mathrm{DO}_{2}$.

\section{Cardiac arrhythmias}

The low incidence of ventricular fibrillation (VF) in our model may be ascribed as species-specific. However, it is likely that the deep anesthetic state protected against cardiac arrhythmias, as catecholamines, especially epinephrine, from both endogenous and exogenous sources have been proven to illicit VF during experimental surface cooling $[45,46]$.

\section{Oxygen variables}

There is no evidence in our material that global oxygen consumption at any time was dependent on oxygen delivery. Two facts support this statement: i) oxygen content of mixed venous blood increased during hypothermia, and ii) the difference in oxygen content between arterial and mixed venous blood in the hypothermic animals was no different from timematched normothermic controls. Previous experiments in our laboratory have demonstrated that increased oxygen extraction from mammalian arterial blood is possible at temperatures as low as $15^{\circ} \mathrm{C}$ [30]. Further, while the present study relates to global variables, it has been shown that in dogs cooled to $25^{\circ} \mathrm{C}$, no myocardial oxygen or substrate deficits was present [47].

In the present experiments animals shivered during initial cooling and this fact may explain why oxygen consumption was only marginally reduced during this phase of the protocol. In the absence of shivering, the relationship between core temperature and oxygen consumption would probably have been linear rather than taking the observed form of a negative exponential function.

\section{Fluctuations in blood volume}

The temperature-dependent fluctuations in $\mathrm{Hb}$ concentration throughout the experiment could not be attributed to periodic blood loss, as bleeding from instrumentation was minimal and blood sampling was evenly distributed. Also, $\mathrm{Hb}$ concentration changes were unrelated to diuresis, as diuretic output was constant throughout experiments. More likely, changes in $\mathrm{Hb}$ concentration were caused by fluctuations in plasma volume by other mechanisms, as has been reported in the time course of surface cooling $[48,49]$ and rewarming [50]. Our findings of temporarily decreased CVP, EDV and ESV during hypothermia support the assumption that plasma volume was reduced in hypothermia and returned to normal during rewarming.

\section{Biochemical markers}

Animals subjected to cooling and rewarming showed a small, but statistically significant increase in TnT that was not present in time-matched normothermic controls. One may suggest that the observed increase in $\mathrm{TnT}$ was due to $\mathrm{Ca}^{2+}$ mediated activation of intracellular proteases that 
degrade troponins in the same manner as has been suggested to take place during myocardial stunning [33].

Post-hypothermic increase in TNF- $\alpha$ and reduced plasma albumin concentration in our experiment may indicate activation of inflammatory mediators by cooling-rewarming, as has been shown in both surface- and endovascular - cooling in the same species $[48,51]$.

\section{Cooling and rewarming rates}

A cooling rate of about $6^{\circ} \mathrm{C}$ per hour, as in the present experiments, is faster than in induced therapeutic hypothermia [7], but appears comparable to that in victims of accidental immersion hypothermia. The rewarming rate of $6.0 \pm 0.3^{\circ} \mathrm{C} / \mathrm{h}$ in our experiment is, however, much faster than that achieved by active external rewarming in clinical settings, where immersion in hot water is seldom used. Kornberger et al. refer to 15 victims of severe accidental hypothermia rewarmed by forced air at a mean rate of $1.7^{\circ} \mathrm{C}$ per hour [20]. Furthermore, they reported no incidents of core temperature afterdrop after the start of external rewarming [20], which is in accordance with findings in this study. Our results do not support that fear of core temperature afterdrop should dictate a particular slow rewarming rate.

\section{Conclusions}

Surface cooling to $25^{\circ} \mathrm{C}$ followed by rewarming resulted in reduced systolic, but not diastolic, LV function. The post-hypothermic increase in heart rate and the reduced systemic vascular resistance are interpreted as adaptive measures by the organism to compensate for a hypothermia-induced mild left ventricular cardiac failure.

\section{Key messages}

- Cardiac left ventricular contractility decreases during surface cooling below $34^{\circ} \mathrm{C}$.

- Cardiac systolic function is depressed after rewarming from $25^{\circ} \mathrm{C}$.

- Cardiac diastolic function is restored after rewarming from $25^{\circ} \mathrm{C}$.

- Post-hypothermic cardiac output is maintained by increased heart rate.

- Decreased post-hypothermic systemic vascular resistance may be adaptive measure.

\footnotetext{
Abbreviations

CO: cardiac output; CVP: central venous pressure; $\mathrm{DO}_{2}$ : global delivery of oxygen; $\mathrm{dP} / \mathrm{dt}_{\max }$ : maximal acceleration of pressure in the cardiac cycle; $\mathrm{dP}$ / $\mathrm{dt}_{\text {min }}$ : maximal deceleration of pressure in the cardiac cycle; $E_{\mathrm{a}}$ : arterial elastance; $E_{a} / E_{e s}$ : arterial-ventricular coupling ratio; $E_{e s}$ : end systolic elastance: slope of the linear ESPVR for a family of PV-loops during VCO; EDP: end diastolic pressure; EDPVR: end diastolic pressure volume relationship; EDV: end diastolic volume: in the present paper consisting of LV end diastolic
}

volume and the volume of surrounding structures; ESP: end systolic pressure; ESV: end systolic volume: in the present paper consisting of LV end systolic volume and the volume of surrounding structures; ESPVR: end systolic pressure volume relationship; Hb: hemoglobin; HR: heart rate; LV: left ventricular; MAP: mean arterial pressure; PRSW: preload recruitable stroke work; PV: pressure-volume; SV: stroke volume; SVR(I): systemic vascular resistance (index); Tau: isovolumetric relaxation time; TNF- $\alpha$ : serum tumour necrosis factor alpha; TnT: serum cardiac troponin $T_{;} V_{0}$ : volume axis intercept of the ESPVR slope determined by PV-loops during VCO; VCO: vena cava occlusion: abrupt occlusion of the inferior caval vein to obtain PVloops; VF: ventricular fibrillation; $\mathrm{VO}_{2}$ : global consumption of oxygen.

\section{Acknowledgements}

We highly appreciate the technical support from Knut Steinnes and Harry Jensen in sampling and analysis of hemodynamic data and the assistance of Hege Hagerup, Janne Andreassen and Jenny Duanthang in carrying out experiments and collection and processing of blood samples.

This research project was supported by grants from the Norwegian Council on Cardiovascular Diseases and the Norwegian Society of Anaesthesiology.

\section{Author details}

${ }^{1}$ Department of Anesthesiology, Institute of Clinical Medicine, University of Tromsø, N-9037 Tromsø, Norway. 'Department of Medical Physiology, Institute of Medical Biology, University of Troms $\varnothing$, N-9037 Tromsø, Norway. ${ }^{3}$ Department of Anesthesiology, University Hospital of Northern Norway, N9038 Tromsø, Norway. ${ }^{4}$ Department of Cardiothoracic surgery, Institute of Clinical Medicine, University of Tromsø, N-9037 Tromsø, Norway.

\section{Authors' contributions}

OMF conducted the experiments and, together with $\Pi$, designed the protocol, discussed the data and wrote the manuscript. OJH took part in protocol and scientific discussions, assisted in carrying out experiments and contributed to the writing process. TK took part in carrying out experiments and processing and interpretation of data. TMG took part in protocol discussions and in carrying out experiments. All authors read and approved the final manuscript.

\section{Competing interests}

The authors declare that they have no competing interests.

Received: 26 February 2010 Revised: 23 September 2010 Accepted: 23 November 2010 Published: 23 November 2010

\section{References}

1. Kornberger E, Mair P: Important aspects in the treatment of severe accidental hypothermia: the Innsbruck experience. J Neurosurg Anesthesiol 1996, 8:83-87.

2. Gilbert M, Busund R, Skagseth A, Nilsen PA, Solbo JP: Resuscitation from accidental hypothermia of 13.7 degrees $C$ with circulatory arrest. Lancet 2000, 355:375-376.

3. ECC Committee, Subcommittees and Task Forces of the American Heart Association: 2005 American Heart Association Guidelines for Cardiopulmonary Resuscitation and Emergency Cardiovascular Care. Circulation 2005, 112:IV1-IV203, Part 10.4: Hypothermia. 112:IV136..

4. Wong KC: Physiology and pharmacology of hypothermia. West J Med 1983, 138:227-232.

5. Laub GW, Banaszak D, Kupferschmid J, Magovern GJ, Young JC: Percutaneous cardiopulmonary bypass for the treatment of hypothermic circulatory collapse. Ann Thorac Surg 1989, 47:608-611.

6. Vassal T, Benoit-Gonin B, Carrat F, Guidet B, Maury E, Offenstadt G: Severe accidental hypothermia treated in an ICU: prognosis and outcome. Chest 2001, 120:1998-2003.

7. Polderman KHM, Herold IM: Therapeutic hypothermia and controlled normothermia in the intensive care unit: Practical considerations, side effects, and cooling methods. Crit Care Med 2009, 37:1101-1120.

8. Chernow B, Lake CR, Zaritsky A, Finton CK, Casey L, Rainey TG, Fletcher JR: Sympathetic nervous system "switch off" with severe hypothermia. Crit Care Med 1983, 11:677-680

9. Thoresen M, Satas S, Løberg EM, Whitelaw A, Acolet D, Lindgren C, Penrice J, Robertsen N, Haug AE, Steen PA: Twenty-Four Hours of Mild Hypothermia in Unsedated Newborn Pigs Starting after a Severe Global 
Hypoxic-Ischemic Insult Is Not Neuroprotective. Pediatric Res 2001 50:405-411.

10. Tooley JR, Satas S, Porter H, Silver IA, Thoresen M: Head cooling with mild systemic hypothermia in anesthetized piglets is neuroprotective. Ann Neurol 2003, 53:65-72.

11. Locher $T$, Walpoth B, Pfluger D, Althaus U: Accidental hypothermia in Switzerland (1980-1987) - case reports and prognostic factors. Schweiz Med Wochenschr 1991, 121:1020-1028.

12. Monroe RG, Strang RH, LaFarge CG, Levy J: Ventricular performance, pressure-volume relationships, and $\mathrm{O} 2$ consumption during hypothermia. Am J Physiol 1964, 206:67-73.

13. Mattheussen M, Mubagwa K, Van Aken H, Wusten R, Boutros A, Flameng W: Interaction of heart rate and hypothermia on global myocardial contraction of the isolated rabbit heart. Anesth Analg 1996, 82:975-981.

14. Post H, Schmitto J, Steendijk P, Christoph J, Holland R, Wachter R, Schondube FW, Pieske B: Cardiac function during mild hypothermia in pigs: Increased iontropy at the expense of diastolic dysfunction. Acta Physiologica 2010, 199:43-52.

15. Nishimura Y, Naito Y, Nishioka T, Okamura Y: The effects of cardiac cooling under surface-induced hypothermia on the cardiac function in the in situ heart. Interact CardioVasc Thorac Surg 2005, 4:101-105.

16. Goldberg LI: Effects of Hypothermia on Contractility of the Intact Dog Heart. Am J Physiol 1958, 194:92-98

17. Ning XH, Hyyti O, Ge M, Anderson DL, Portman M: Rapid progressive central cooling to $29^{\circ} \mathrm{C}$ by extracorporeal circuit preserves cardiac function and hemodynamics in immature swine. Resuscitation 2008, 76:443-448.

18. Tveita T, Ytrehus K, Myhre ES, Hevroy O: Left ventricular dysfunction following rewarming from experimental hypothermia. J Appl Physiol 1998, 85:2135-2139.

19. Goetzenich A, Schroth SC, Emmig U, Autschbach R, Pieske B, Rossaint R, Christiansen S: Hypothermia exerts negative inotropy in human atrial preparations: in vitro-comparison to rabbit myocardium. J Cardiovasc Surg (Torino) 2009, 50:239-245.

20. Kornberger $E$, Schwarz B, Lindner KH, Mair P: Forced air surface rewarming in patients with severe accidental hypothermia. Resuscitation 1999, 41:105-111.

21. Popovic VP, Kent KM: Cardiovascular responses in prolonged hypothermia. Am J Physiol 1965, 209:1069-1074.

22. Fedor EJ, Fisher B, Lee SH: Rewarming following hypothermia of two to twelve hours. I. Cardiovascular effects. Ann Surg 1958, 147:515-530.

23. Steen PA, Milde JH, Michenfelder JD: The detrimental effects of prolonged hypothermia and rewarming in the dog. Anesthesiology 1980, 52:224-230.

24. Tveita T, Skandfer M, Refsum H, Ytrehus K: Experimental hypothermia and rewarming: changes in mechanical function and metabolism of rat hearts. J Appl Physiol 1996, 80:291-297.

25. Kondratiev TV, Myhre ES, Simonsen O, Nymark TB, Tveita T: Cardiovascular effects of epinephrine during rewarming from hypothermia in an intact animal model. J Appl Physiol 2006, 100:457-464.

26. Kelley KW, Curtis SE, Marzan GT, Karara HM, Anderson CR: Body Surface Area of Female Swine. J Anim Sci 1973, 36:927-930.

27. Strohmer B, Pichler M: Atrial fibrillation and prominent J (Osborn) waves in critical hypothermia. Int J Cardiol 2004, 96:291-293.

28. Lab MJ, Seed WA: Pulsus alternans. Cardiovasc Res 1993, 27:1407-1412.

29. Sessler DIM: Thermoregulatory defense mechanisms. Crit Care Med 2009, 37:S203-S210.

30. Kondratiev TV, Flemming K, Myhre ES, Sovershaev MA, Tveita T: Is oxygen supply a limiting factor for survival during rewarming from profound hypothermia? Am J Physiol Heart Circ Physiol 2006, 291:H441-H450.

31. Popovic V: Survival time of hypothermic white rats $\left(15^{\circ} \mathrm{C}\right)$ and ground squirrels (10 C). Am J Physiol 1960, 199:463-466

32. Kondratiev TV, Wold RM, Aasum E, Tveita T: Myocardial mechanical dysfunction and calcium overload following rewarming from experimental hypothermia in vivo. Cryobiology 2008, 56:15-21.

33. Bolli R, Marban E: Molecular and cellular mechanisms of myocardial stunning. Physiol Rev 1999, 79:609-634.

34. Aghajani E, Muller S, Kjorstad KE, Korvald C, Nordhaug D, Revhaug A, Myrmel T: The pressure-volume loop revisited: Is the search for a cardiac contractility index a futile cycle? Shock 2006, 25:370-376.
35. Kjorstad KE, Korvald C, Myrmel T: Pressure-volume-based single-beat estimations cannot predict left ventricular contractility in vivo. Am J Physiol Heart Circ Physiol 2002, 282:H1739-H1750.

36. Puglisi JL, Bassani RA, Bassani JW, Amin JN, Bers DM: Temperature and relative contributions of $\mathrm{Ca}$ transport systems in cardiac myocyte relaxation. Am J Physiol 1996, 270:H1772-H1778.

37. Przyklenk K, Patel B, Kloner RA: Diastolic abnormalities of postischemic "stunned" myocardium. Am J Cardiol 1987, 60:1211-1213.

38. Lewis ME, Al Khalidi AH, Townend JN, Coote J, Bonser RS: The effects of hypothermia on human left ventricular contractile function during cardiac surgery. J Am Coll Cardiol 2002, 39:102-108.

39. Opie LH: The Heart Philadelphia, PA: Lippincott-Raven; 1998.

40. Tavazzi L, Maggioni AP, Lucci D, Cacciatore G, Ansalone G, Oliva F, Porcu M: Nationwide survey on acute heart failure in cardiology ward services in Italy. Eur Heart J 2006, 27:1207-1215.

41. Legault F, Rouleau JL, Juneau C, Rose C, Rakusan K: Functional and morphological characteristics of compensated and decompensated cardiac hypertrophy in dogs with chronic infrarenal aorto-caval fistulas. Circ Res 1990, 66:846-859.

42. Maclean D, Emslie-Smith D: Accidental hypothermia London: JB Lippincott Co; 1977.

43. Chantler PD, Lakatta EG, Najjar SS: Arterial-ventricular coupling: mechanistic insights into cardiovascular performance at rest and during exercise. J Appl Physiol 2008, 105:1342-1351

44. Borlaug BA, Kass DA: Ventricular-Vascular Interaction in Heart Failure. Heart Failure Clinics 2008, 4:23-36.

45. Angelakos ET, Daniels JB: Effect of catecholamine infusions on letha hypothermic temperatures in dogs. J Appl Physiol 1969, 26:194-196.

46. Warner WA, Anton AH, Andersen TW, Swofford LJ: Ventricular fibrillation and catecholamine responses during profound hypothermia in dogs. Anesthesiology 1970, 33:43-51.

47. Tveita T, Mortensen E, Hevroy O, Refsum $H$, Ytrehus K: Experimental hypothermia: effects of core cooling and rewarming on hemodynamics, coronary blood flow, and myocardial metabolism in dogs. Anesth Analg 1994, 79:212-218

48. Chen RY, Chien S: Plasma volume, red cell volume, and thoracic duct lymph flow in hypothermia. Am J Physiol 1977, 233:H605-H612.

49. Hammersborg SM, Farstad M, Haugen O, Kvalheim V, Onarheim H, Husby P. Time course variations of haemodynamics, plasma volume and microvascular fluid exchange following surface cooling: an experimental approach to accidental hypothermia. Resuscitation 2005, 65:211-219.

50. Lauri T: Cardiovascular responses to an acute volume load in deep hypothermia. Eur Heart J 1996, 17:606-611.

51. Hammersborg SM, Brekke HK, Haugen Or, Farstad M, Husby P: Surface cooling versus core cooling: Comparative studies of microvascular fluidand protein-shifts in a porcine model. Resuscitation 2008, 79:292-300

doi:10.1186/cc9334

Cite this article as: Filseth et al:: Post-hypothermic cardiac left ventricular systolic dysfunction after rewarming in an intact pig model. Critical Care 2010 14:R211.

\section{Submit your next manuscript to BioMed Central and take full advantage of:}

- Convenient online submission

- Thorough peer review

- No space constraints or color figure charges

- Immediate publication on acceptance

- Inclusion in PubMed, CAS, Scopus and Google Scholar

- Research which is freely available for redistribution

Submit your manuscript at www.biomedcentral.com/submit
C Biomed Central 